\title{
Paste backfill design case study — Efemçukuru project
}

\author{
J.M. Treinen Paterson \& Cooke Ltd, United States of America \\ R. Cooke Paterson \& Cooke Ltd, United States of America \\ D. Sutherland Eldorado Gold, Canada
}

\begin{abstract}
Paterson \& Cooke completed the basic engineering of the paste backfill reticulation system for Eldorado Gold's Efemçukuru project in Turkey. This paper presents a case study of the project. Test work was completed to characterise the paste flow behaviour and compressive strength behaviour. Hydraulic analysis and design, based on homogeneous slurry behaviour, allowed for the specification of the piston pumping requirements and identified potential problematic slack flow conditions. Operational, as well as seismic loading scenarios were taken into account during the stress analysis and mechanical design.
\end{abstract}

\section{Introduction}

The Efemçukuru gold project is located in western Turkey near the city of Izmir and is wholly owned by Eldorado Gold Corp. The project is currently under construction, and production is expected in late 2010. Approximately half of the tailings produced from the operation will be processed for paste backfill to be used as working floors within the mine. This paper presents a case study of the backfill system design including the test work, hydraulic analysis, and mechanical design.

\section{$2 \quad$ Paste test work}

The first step in completing the paste reticulation system design was characterising the paste properties. The paste rheology and the cured compressive strength properties were measured over a range of concentrations and binder contents. Table 1 summarises the test work matrix. Slump is often used as a quality control during paste preparation, so tests using both a standard $305 \mathrm{~mm}$ ASTM slump cone and a $75 \mathrm{~mm}$ Boger slump cylinder were completed. The vane yield stress was measured with a Haake Viscotester 550 viscometer using a four blade FL-100 vane attachment.

The unconfined compressive strength (UCS) was tested over a range of binder contents and cure times, to provide an indication of the cement required to achieve suitable backfill strengths for different stope turnaround times. Ordinary Portland cement was used as the binder.

\subsection{Rheology characterisation}

Based on the rheology test work, the paste is classified as a homogeneous, non-settling Bingham plastic slurry. The material properties are detailed in Table 2. Figure 1 shows the measured vane yield stress as a function of solids concentration. Note, that over the small concentration range of $2.5 \% \mathrm{~m}$ a linear trend can be seen. In actuality, over a larger concentration range, the yield stress will exhibit a power law relationship when compared to concentration, with a very little increase in concentration resulting in a significant increase in yield stress. The figure also indicates that the binder content has only a small impact on the vane yield stress, at least at the concentrations considered in the test campaign, and the biggest influence is the total mass concentration. The vane yield stress is within the typical values expected for paste backfill material. 
Table 1 Paste test work matrix

\begin{tabular}{lllll}
\hline $\begin{array}{l}\text { ASTM } \\
\text { Slump }\end{array}$ & $\begin{array}{l}\text { 2\% Binder } \\
\text { Content }\end{array}$ & $\mathbf{4 \%}$ Binder Content & $\begin{array}{l}\mathbf{6 \%} \text { Binder } \\
\text { Content }\end{array}$ & 8\% Binder Content \\
\hline $203 \mathrm{~mm}$ & & ASTM slump & & ASTM slump \\
& & Boger slump & Boger slump \\
& & Vane yield stress & & Vane yield stress \\
& & UCS (28 day) & & UCS (28 day) \\
$178 \mathrm{~mm}$ & ASTM slump & ASTM slump & ASTM slump & ASTM slump \\
& Boger slump & Boger slump & Boger slump & Boger slump \\
& Vane yield stress & Vane yield stress & Vane yield stress & Vane yield stress \\
& UCS (28 day) & UCS (7, 14, 28, 90 day) & UCS (28 day) & UCS (7, 14, 28, 90 day) \\
$152 \mathrm{~mm}$ & & ASTM slump cone & & ASTM slump \\
& & Boger slump cone & & Boger slump \\
& & Vane yield stress & & Vane yield stress \\
& & UCS (28 day) & & UCS (28 day) \\
\hline
\end{tabular}

Table 2 Paste material properties

\begin{tabular}{ll}
\hline Property & Value \\
\hline Solids specific gravity & 2.94 \\
$\mathrm{~d}_{90}$ particle size & $73 \mu \mathrm{m}$ \\
$\mathrm{d}_{85}$ particle size & $66 \mu \mathrm{m}$ \\
$\mathrm{d}_{50}$ particle size & $22 \mu \mathrm{m}$ \\
$\%-20 \mu \mathrm{m}$ & $47.4 \%$ \\
Average paste $\mathrm{pH}$ & 7.8 (without cement) \\
& 11.8 (with cement) \\
& \\
\end{tabular}

\subsection{Unconfined compressive strength}

The unconfined compressive strength of the paste was measured using $50 \times 100 \mathrm{~mm}$ compression specimens, according to ASTM D4832-02. Considering both the overall solids concentration, and binder content, the measured compressive strength values are plotted in Figure 2 as a function of the water to cement ratio, defined as the mass of water over the mass of cement in the paste. As shown by the figure, the strength is highly dependent on this ratio.

Figure 3 presents the unconfined strength as a function of cure time. The higher binder content paste took longer to reach full strength when compared with the lower binder content paste. For this particular paste, doubling the binder content results in an average $260 \%$ increase in compressive strength. The strength increase ranges from 210 to $320 \%$ when compared over cure times, due to the experimental scatter and longer curing time required for the higher binder content paste. 


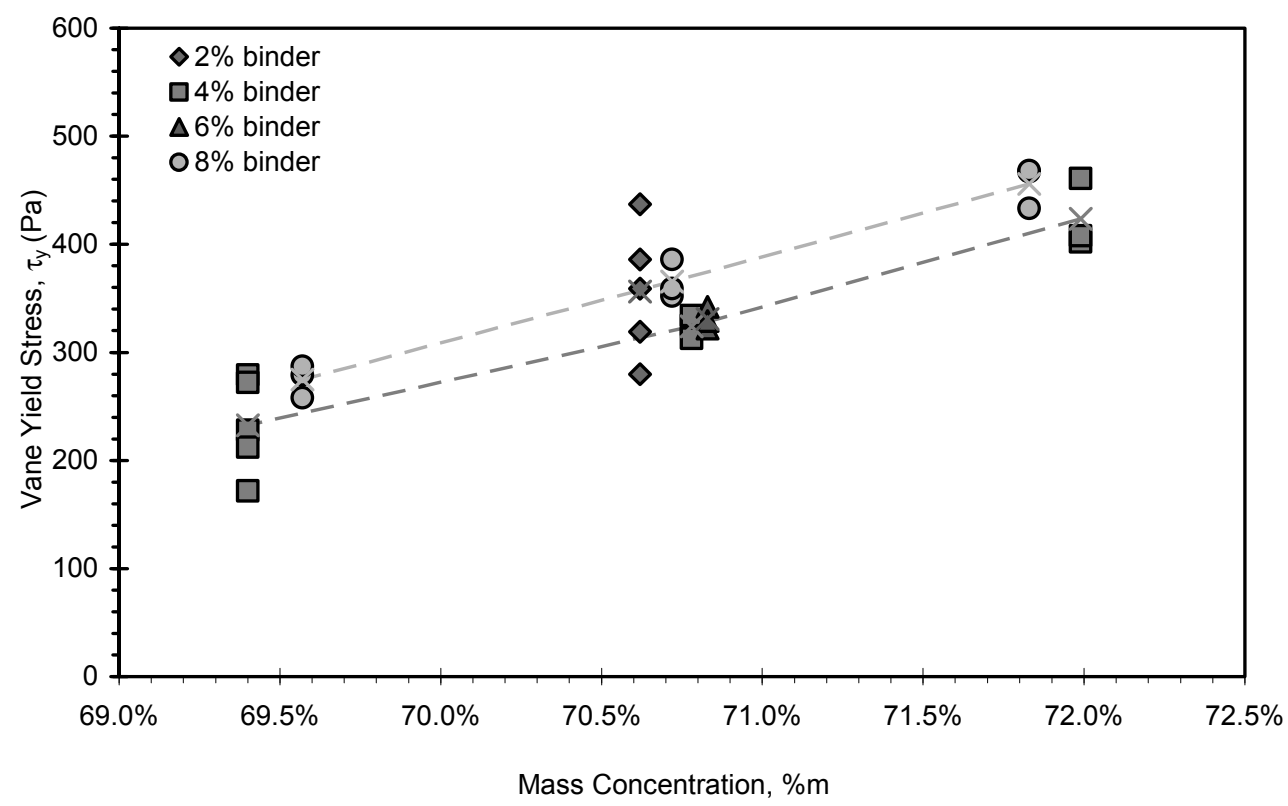

Figure 1 Vane yield stress as a function of mass concentration over a range of binder concentrations

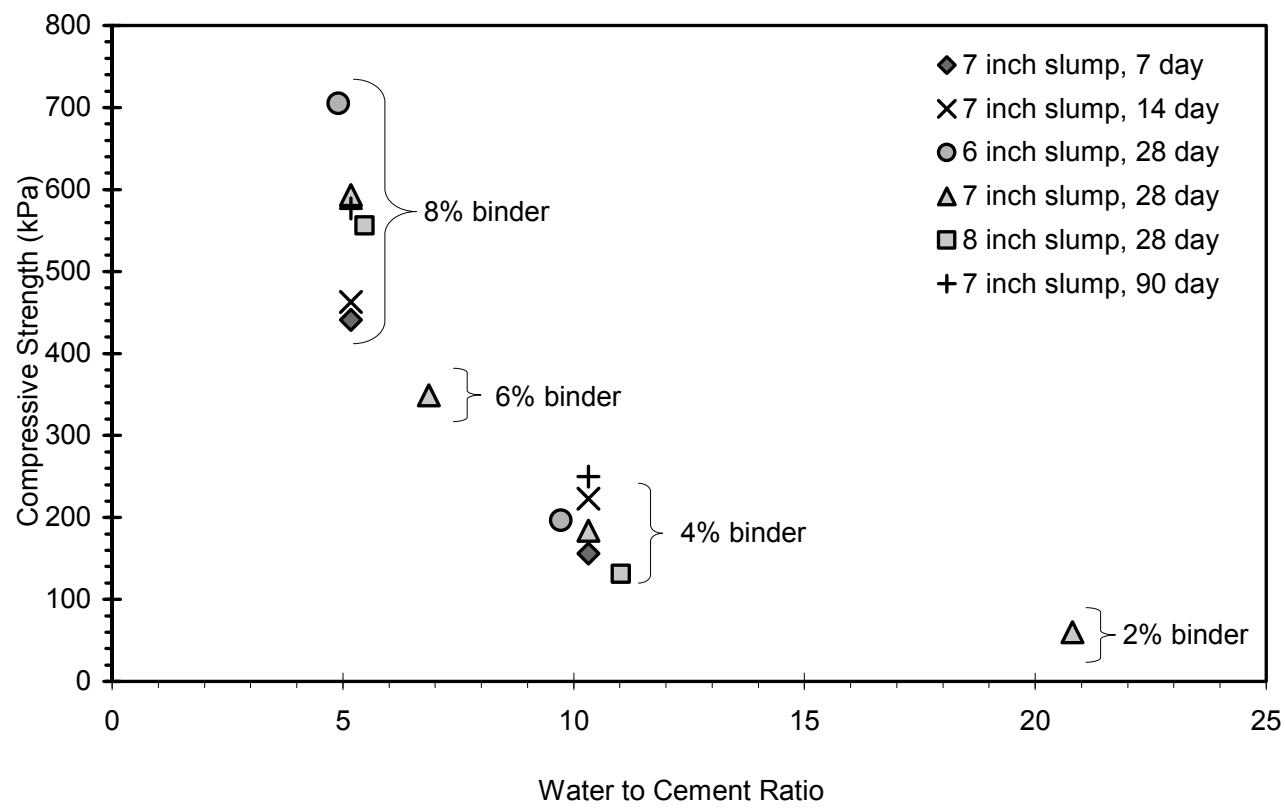

Figure 2 Compressive strength versus water to cement ratio 


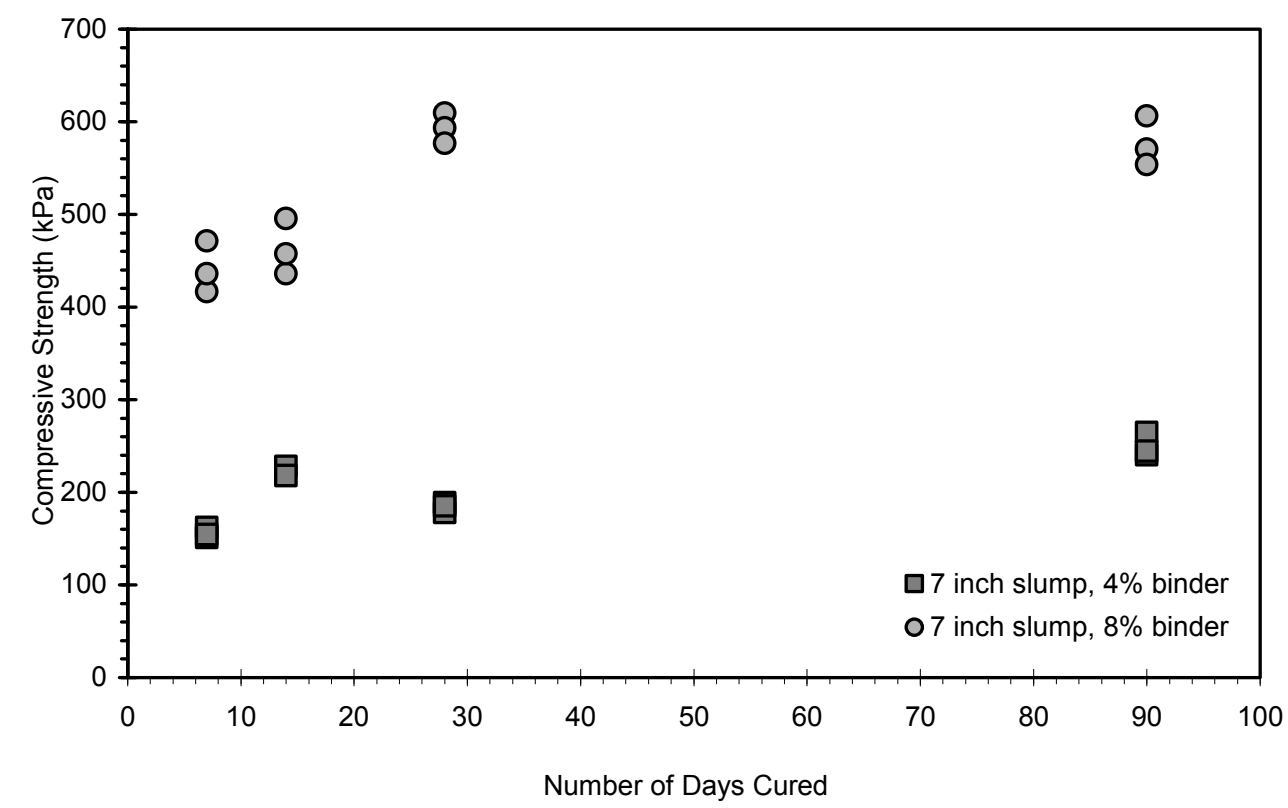

Figure 3 Compressive strength versus curing time

\section{$3 \quad$ Hydraulic design}

\subsection{Operating parameters}

The operating parameters used in the system are detailed in Table 3.

\section{Table 3 Backfill operating parameters}

\begin{tabular}{ll}
\hline Parameter & Value \\
\hline Tonnage & $45-48 \mathrm{t} / \mathrm{h}$ (varies by binder) \\
Mass concentration & $69.6 \% \mathrm{~m}$ \\
Paste yield stress & $233 \mathrm{~Pa}$ \\
Paste plastic viscosity & $100 \mathrm{mPa} . \mathrm{s}$ (assumed) \\
Flow rate & 35 to $37 \mathrm{~m}^{3} / \mathrm{hr}$ (varies by binder) \\
Binder content & 2 to $8 \%$ \\
\hline
\end{tabular}

\subsection{Pipeline routing}

Using a three dimensional CAD layout, it was possible to route the piping to different stopes in the mine. The routes were discretised as individual piping elements and could be connected to make up the entire piping network. Figure presents a schematic of the overall piping system. The routes primarily followed haulage ramps and ventilation rises to facilitate easier installation. However, where they significantly shortened the piping distance, boreholes between levels were utilised. The discharge stopes range in elevation from $18 \mathrm{~m}$ above the paste plant to $314 \mathrm{~m}$ below it. The longest pipeline route within the mine is approximately $1,000 \mathrm{~m}$, while the shortest is $340 \mathrm{~m}$.

There are three separate mine regions, and two pipelines from the paste plant are used to access the mine stopes. One route services the north region while the second services the central and south regions. Providing two pipelines allows for greater system availability since paste can be discharged into one region while the other region's pipeline route is reconfigured for the next stope. 


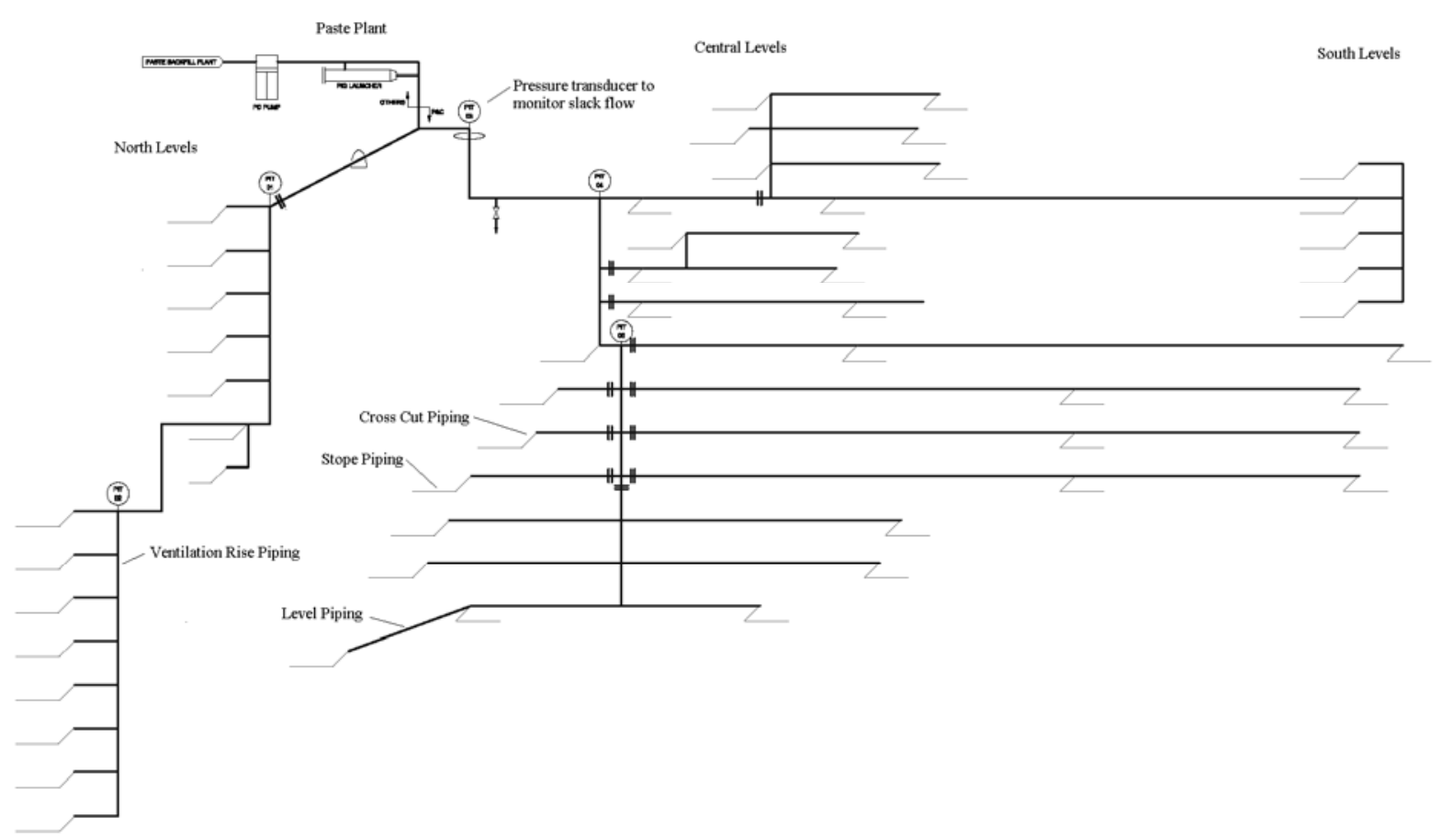

\section{Figure 4 Schematic of piping system}

\subsection{Pipe selection}

The pipe size is based on the expected paste flow rate from the paste plant and predicted friction losses. The line was sized so the flow velocity was near $1.0 \mathrm{~m} / \mathrm{s}$. At $1.0 \mathrm{~m} / \mathrm{s}$ the flow is sufficient to provide an appropriate residence time while limiting the friction losses and therefore pumping pressures. Based on the pressure requirements for the different parts of the system, four different pipe types have been specified for the system, as detailed in Table 4.

The majority of the system is specified to be API Grade B pipe with schedule 40 wall thickness. However, the initial piping from the pump discharge for approximately $180 \mathrm{~m}$ is higher pressure schedule 80 pipe, to accommodate the high line pressures. For convenience, mechanical end groove couplings have been specified to join the pipe segments. Flexible couplings are specified for the piping within the cross cuts and stopes, as this piping will be disconnected frequently and the flexible couplings provide greater allowance for misalignment. In the same regard, high density polyethylene (HDPE) piping is specified for the stope piping.

Table 4 Pipe type specifications for backfill system

\begin{tabular}{llllll}
\hline Pipe & Material & ID & Coupling & $\begin{array}{l}\text { Pipe Friction } \\
\text { Loss }\end{array}$ & $\begin{array}{l}\text { Pressure } \\
\text { Rating }\end{array}$ \\
\hline $200 \mathrm{~mm}$ Sch 80 & Steel & $96.8 \mathrm{~mm}$ & Rigid & $11.32 \mathrm{kPa} / \mathrm{m}$ & $17.2 \mathrm{MPa}$ \\
$200 \mathrm{~mm}$ Sch 40 & Steel & $101.9 \mathrm{~mm}$ & Rigid & $10.62 \mathrm{kPa} / \mathrm{m}$ & $6.9 \mathrm{MPa}$ \\
$200 \mathrm{~mm}$ Sch 40 & Steel & $101.9 \mathrm{~mm}$ & Flexible & $10.62 \mathrm{kPa} / \mathrm{m}$ & $6.9 \mathrm{MPa}$ \\
$250 \mathrm{~mm}$ SDR 5 & HDPE & $100.9 \mathrm{~mm}$ & Flexible & $10.76 \mathrm{kPa} / \mathrm{m}$ & $1.8 \mathrm{MPa}$ \\
\hline
\end{tabular}

\subsection{Pumping requirements}

Using Paterson \& Cooke's proprietary hydraulic calculation spreadsheet, the hydraulic grade lines and resulting pump discharge pressures were calculated for each of the stopes where paste is to be discharged. By 
iterating through the different discharge points and updating the pipe routes and pressure ratings required, the pumping requirements of the system were determined.

The maximum pump discharge pressure was found to be approximately $6.8 \mathrm{MPa}$. To achieve this pumping pressure for the flow rates in Table4, a piston type positive displacement pump was specified. Figure provides an overview of the pumping pressure requirements for a range of stope discharge points at the minimum, average, and maximum length of piping within the stope.

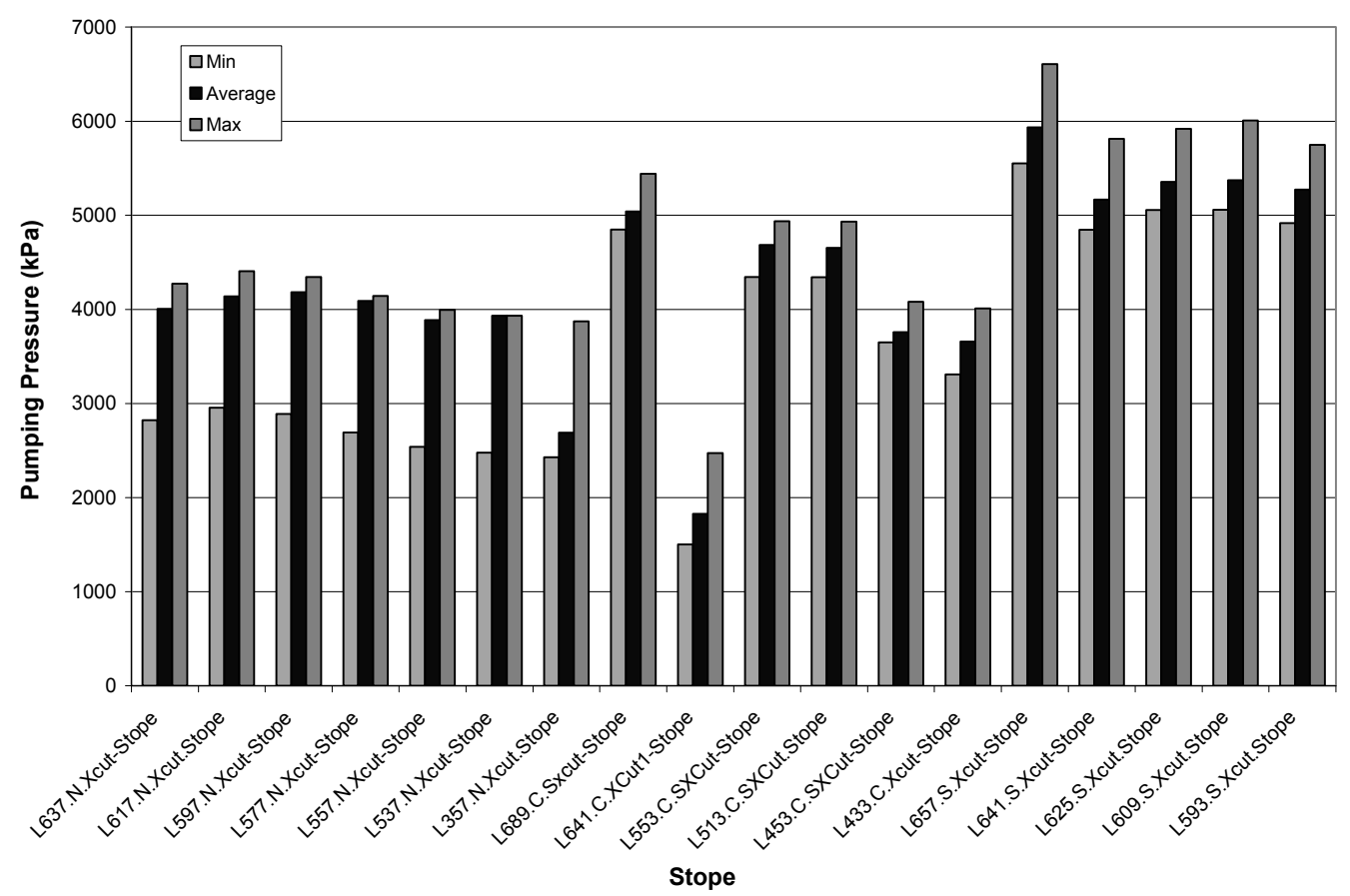

Figure 5 Summary of pump discharge pressures

\subsection{Slack flow considerations}

One of the primary sources of pipeline wear in backfill systems is slack flow, resulting in higher maintenance costs and lost production time. Slack flow, where the pressure within the pipeline drops to the vapour pressure of the liquid and the pipeline becomes only partially filled, generally occurs in areas where the elevation of the pipeline decreases significantly over a relatively short section of pipe. The pipeline velocity in these areas can increase to up to $11 \mathrm{~m} / \mathrm{s}$. Because the wear rate in slurry pipelines has typically been found to be proportional to the velocity to the 2.5 power, operating in slack flow can significantly shorten the useful life of the pipe.

In the design of the Efemçukuru backfill system, long vertical sections of pipe, primarily located in ventilation raises, are susceptible to slack flow. To prevent slack flow from occurring, it may be necessary to route the pipe out of the ventilation rise toward the bottom of it and along the more gradually sloped haulage ramps. This provides additional back-pressure at the bottom of the ventilation rise to prevent the slack flow. Alternatively, it is possible to prevent slack flow by increasing the solids concentration, which increases the pipeline friction loss.

By monitoring pressure transducers installed at the top of the longer ventilation rises, it will be possible for the operators to monitor and correct the slack flow conditions before significant wear occurs in the pipeline.

\subsection{Flushing}

The final area of interest in the hydraulic design is flushing. For all but a few stopes that are actually higher in elevation than the paste plant, the system is flushed by pumping water, using the mainline piston paste pump, into the piping, until the discharge pressure of the pump drops to atmospheric pressure. At that point, the pump can be stopped, and the remainder of the system will flush under gravity flow. For the few stopes 
higher in elevation than the paste plant, the pump must be operated until flush water reaches the end of the pipeline.

A pump failure could potentially result in paste hardening in the pipeline, so a backup pump dedicated only to flushing the system has been specified. It is only used for flushing in emergency events, and therefore a water pump, with half the flow capacity but same pressure rating, is suitable.

Drain valves are to be installed at the low points of the distribution system, as any remaining paste and flush water must be completely drained from the system during shut down.

\section{$4 \quad$ Mechanical design}

The mechanical design of the system covers the stress analysis of both the above ground and underground pipeline sections. The analysis verifies that the stress on the pipeline is within accepted design codes, in particular the ASME B31.3 process piping code, and also provides reaction forces so appropriate guides and anchors can be specified. Note that while ASME B31.11 is typically used for overland slurry pipelines, B31.3 is more appropriate for high pressure piping in close proximity to personal, such as backfill operations.

\subsection{Above ground supports}

The pipeline routing above ground is complex and subject to significant temperature variations, so the CAESAR II pipe stress software package (COADE, 2007) was used for the stress analysis. Table 5 summarises the loads acting on the above ground pipe section. The stress analysis was completed by applying various combinations of the loads, to produce the worst case scenario, and positioning pipe anchor and guide supports along the above ground piping to allow adequate flexibility in the system.

\section{Table 5 Above ground mechanical design parameters}

\begin{tabular}{lll}
\hline Load & Load Type & Value \\
\hline Pipe weight & Sustained & - \\
Slurry weight & Sustained & - \\
Operating pressure & Sustained & $6.7 \mathrm{MPa}$ \\
Max operating pressure & Sustained & $8.5 \mathrm{MPa}$ \\
Temperature range, empty pipe & Thermal expansion & $0-60^{\circ} \mathrm{C}$ \\
Temperature range, full pipe & Thermal expansion & $10-30^{\circ} \mathrm{C}$ \\
Pump transient loading & Occasional & $15 \mathrm{kN}$ \\
Earthquake loading & Occasional & $0.28 \mathrm{~g}$ \\
\hline
\end{tabular}

\subsection{Below ground supports}

The below ground pipeline configuration will be frequently changed, so only the worst case stress analysis scenario was investigated. This investigation included analysing the loads acting on the piping anchors, installed shortly after the piping enters the level from the ventilation raise or borehole from which it came. The anchors were designed to withstand the maximum operating and earthquake loads the pipe is subjected to for the longest piping run in the system. Since the actual earthquake loading is unknown, compressive pipeline buckling was considered in addition to tensile failure. The analysis indicated that guides should be located every 18 to $24 \mathrm{~m}$ along the drift piping, and the pipe should be suspended from the ceiling using hanging supports placed at $6 \mathrm{~m}$ intervals. 


\section{Conclusions}

The Efemçukuru paste reticulation system design considers both the hydraulics and support layout for the system. The paste test work completed prior to the design provided the necessary test data for the hydraulic analysis. Site conditions and operating parameters enabled appropriate supports, guides and anchors to be specified for the system.

\section{Acknowledgements}

The contributions of the Paterson and Cooke staff in providing significant contributions to the design of the system, in particular Malcolm Keevy and Joshua Stowe are greatly appreciated.

We thank Eldorado Gold for the permission to present this case study.

\section{References}

COADE (2007) Caesar II Pipe Stress Analysis Software, v 5.10 September 2007, COADE Inc, Houston TX. 